Research article Open Access

\title{
Meta-analysis of gene expression profiles in breast cancer: toward a unified understanding of breast cancer subtyping and prognosis signatures
}

\author{
Pratyaksha Wirapati ${ }^{1}$, Christos Sotiriou ${ }^{2}$, Susanne Kunkel ${ }^{1}$, Pierre Farmer ${ }^{1,3}$, Sylvain Pradervand ${ }^{4}$, \\ Benjamin Haibe-Kains ${ }^{2,5}$, Christine Desmedt ${ }^{2}$, Michail Ignatiadis², Thierry Sengstag ${ }^{1,3}$, \\ Frédéric Schütz¹, Darlene R Goldstein ${ }^{1,4,6}$, Martine Piccart² and Mauro Delorenzi1,3
}

\author{
1Swiss Institute of Bioinformatics, 'Batiment Genopode', University of Lausanne, 1015 Lausanne, Switzerland \\ ${ }_{2}^{2}$ Translational Research and Medical Oncology Unit, Université Libre de Bruxelles, Institut Jules Bordet, 121 Boulevard de Waterloo, 1000 Brussels, \\ Belgium \\ ${ }^{3}$ National Centers for Competence in Research, Molecular Oncology, Swiss Institute for Experimental Cancer Research, Ch. des Boveresses 155, \\ 1066 Epalinges, Switzerland \\ 4DNA Array Facility, Center for Integrative Genomics, 'Batiment Genopode', University of Lausanne, 1015 Lausanne, Switzerland \\ ${ }^{5}$ Machine Learning Group, Université Libre de Bruxelles, boulevard du Triomphe, CP212, 1050 Bruxelles, Belgium \\ Institut de Mathématiques, Ecole Polytechnique Fédérale de Lausanne, 1015 Lausanne, Switzerland \\ Corresponding author: Christos Sotiriou, christos.sotiriou@bordet.be
}

Received: 28 Feb 2008 Revisions requested: 28 Apr 2008 Revisions received: 27 May 2008 Accepted: 28 Jul 2008 Published: 28 Jul 2008

Breast Cancer Research 2008, 10:R65 (doi:10.1186/bcr2124)

This article is online at: http://breast-cancer-research.com/content/10/4/R65

(C) 2008 Wirapati et al.; licensee BioMed Central Ltd.

This is an open access article distributed under the terms of the Creative Commons Attribution License (http://creativecommons.org/licenses/by/2.0), which permits unrestricted use, distribution, and reproduction in any medium, provided the original work is properly cited.

\begin{abstract}
Introduction Breast cancer subtyping and prognosis have been studied extensively by gene expression profiling, resulting in disparate signatures with little overlap in their constituent genes. Although a previous study demonstrated a prognostic concordance among gene expression signatures, it was limited to only one dataset and did not fully elucidate how the different genes were related to one another nor did it examine the contribution of well-known biological processes of breast cancer tumorigenesis to their prognostic performance.

Method To address the above issues and to further validate these initial findings, we performed the largest meta-analysis of publicly available breast cancer gene expression and clinical data, which are comprised of 2,833 breast tumors. Gene coexpression modules of three key biological processes in breast cancer (namely, proliferation, estrogen receptor [ER], and HER2 signaling) were used to dissect the role of constituent genes of nine prognostic signatures.
\end{abstract}

Results Using a meta-analytical approach, we consolidated the signatures associated with ER signaling, ERBB2 amplification, and proliferation. Previously published expression-based nomenclature of breast cancer 'intrinsic' subtypes can be mapped to the three modules, namely, the ER-/HER2- (basallike), the HER2 + (HER2-like), and the low- and high-proliferation $\mathrm{ER}^{+} / \mathrm{HER} 2^{-}$subtypes (luminal $\mathrm{A}$ and $\mathrm{B}$ ). We showed that all nine prognostic signatures exhibited a similar prognostic performance in the entire dataset. Their prognostic abilities are due mostly to the detection of proliferation activity. Although ERstatus (basal-like) and ERBB2 ${ }^{+}$expression status correspond to bad outcome, they seem to act through elevated expression of proliferation genes and thus contain only indirect information about prognosis. Clinical variables measuring the extent of tumor progression, such as tumor size and nodal status, still add independent prognostic information to proliferation genes.

Conclusion This meta-analysis unifies various results of previous gene expression studies in breast cancer. It reveals connections between traditional prognostic factors, expressionbased subtyping, and prognostic signatures, highlighting the important role of proliferation in breast cancer prognosis. 


\section{Introduction}

Breast cancer is the disease most extensively studied by gene expression profiling of primary tumors from patient populations [1-21]. Despite this effort, the research results are still fragmented. Disparate signatures have been proposed, either directly from breast cancer expression profiles [10$12,18,19,21,22]$ or translated from model systems [1,23,24], with little agreement in the constituent genes. Fan and colleagues [25] recently compared the prognostic ability of the intrinsic subtypes and four prognostic signatures in 295 patients. They noted concordance in the risk classification, which suggests potential equivalence between some of these signatures. However, these signatures have been examined in only one dataset and the study did not fully elucidate how the different genes were related to one another nor did it examine the contribution of well-known biological processes of breast cancer tumorigenesis to their prognostic performance.

To address these issues, we undertook the largest meta-analysis of publicly available gene expression and clinical data, which are comprised of 2,833 breast tumors [1-21]. We used the concept of 'coexpression' modules (comprehensive lists of genes with highly correlated expression) associated with important biological processes in breast cancer to reveal the common thread connecting molecular subtyping and several prognostic signatures. Their prognostic values, adjusted for the conventional clinicopathological variables, were studied in a database of 2,833 patients with breast cancer in order to arrive at solid conclusions. Finally, we went a step further to characterize the constituent genes of these signatures and to study how they contribute to their prognostic power.

\section{Materials and methods}

Detailed descriptions of the methods can be found in Additional data file 1. A brief summary is outlined here.

\section{Preparation of expression data}

We collected publicly available datasets from journal articles and repositories such as Gene Expression Omnibus (GEO) and ArrayExpress, selecting those with a medium to large sample size (Table 1). Since publications sometimes used the same patients, datasets with unique patients were introduced (identified by the 'dataset symbols' in Table 1) by merging some original datasets or removing redundant patients. The collection includes datasets produced on whole-genome microarrays, small diagnostic arrays, and reverse transcriptionpolymerase chain reaction panels, totaling 2,833 expression profiles. Hybridization probes were mapped to Entrez GenelD [26] through sequence alignment against RefSeq mRNA in the (NM) subset, similar to the approach of Shi and colleagues [27], using RefSeq version 21 (2007.01.21) and Entrez database version 2007.01.21. When multiple probes were mapped to the same GenelD, the one with the highest variance in a particular dataset was selected to represent the GenelD. The numbers of distinct GenelDs obtained for each dataset are shown in Table 1. The normalized, log-transformed expression measures as published by the original studies were used. Meta-analyses were performed on the union of all 17,198 genes. Summary statistics of absent genes were considered as missing values. Summaries of the availability and compositions of important clinical variables for each dataset are shown in Figure 1 of Additional data file 2.

\section{Identifying coexpression modules}

The expression levels of the prototype genes on the $\log _{2}$ scale were used as explanatory variables in multiple regression with the Gaussian error model, using the following equation (gene symbols stand for their log expression, and coefficients are omitted for clarity):

$$
Y_{i}=E S R 1+E R B B 2+A U R K A
$$

where the response variable $Y_{i}$ is the expression of gene $i$. This model is fitted separately for each gene $i$ in the array. The association between gene $i$ and prototype $j$ (in the presence of or conditional on all other prototypes) is tested using the $t$ statistic for each coefficient. Because the $t$ statistics for different datasets have different degrees of freedom, we put them all on the same scale by transforming them to the corresponding cumulative probabilities and then to $z$ scores using the inverse standard normal cumulative distribution function. The $z$ scores were combined meta-analytically across datasets using the 'inverse normal method'. The linear model above was fitted separately to each gene in each dataset, and the $z$ scores were combined meta-analytically over multiple studies using the inverse normal method [28]. To select genes that are most strongly associated with the prototypes, we use a stringent criterion of $|z| \geq 16$, which is well above $|z| \approx 5$ that corresponds to a Bonferroni-corrected $P$ value of 0.05 .

\section{Module scores}

For a specific dataset, the module score is computed for each sample as

$$
\text { module score }=\sum_{i} w_{i} x_{i} / \sum_{i}\left|w_{i}\right|,
$$

where $x_{i}$ is the expression of a gene in the module that is present in the dataset's platform. $w_{i}$ is either +1 or -1 , depending on the sign of the $z$ score of the association with the prototypes.

\section{Clustering and multimodality tests}

To cluster the tumors based on the ESR1 and ERBB2 module scores, Gaussian mixture models [29] with equal and diagonal variance for all clusters were fitted. For testing multimodality, we used the likelihood ratio test statistics between the fitted model for the tested number of components, $k$, versus the alternative model with $k-1$ components. The statistical significance of the number of components was assessed by para- 
(a)

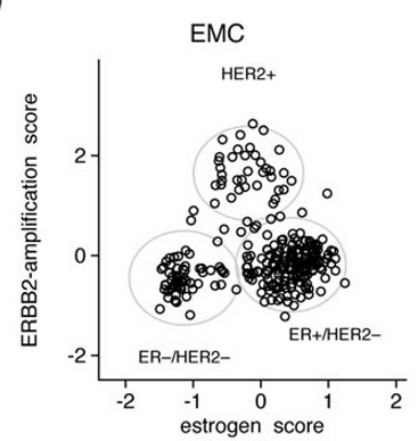

(b)

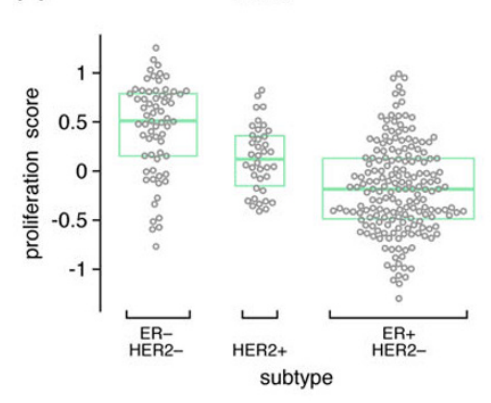

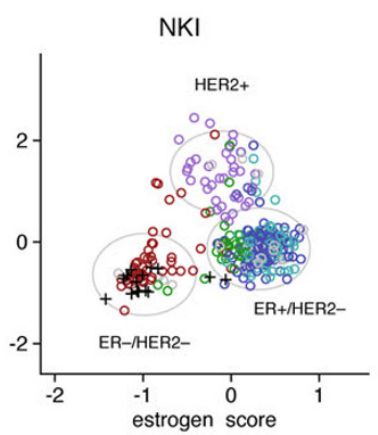

NKI

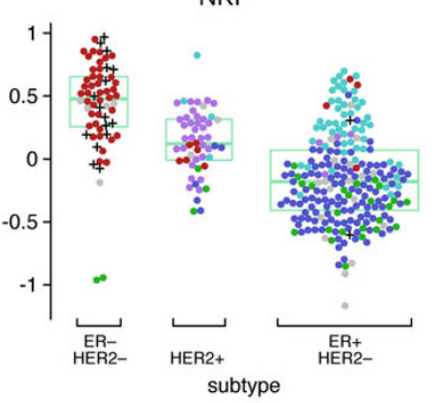

Intrinsic subtype:

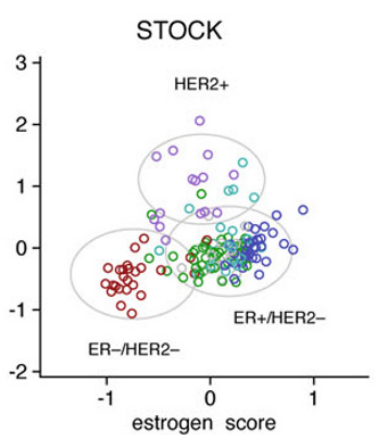

STOCK

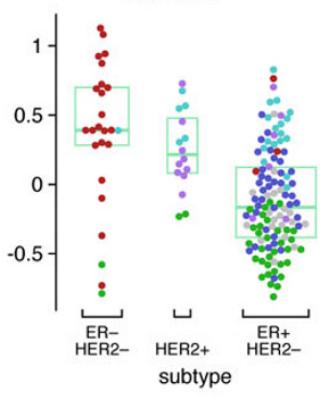

sal-like, her2/neu, luminal A, luminal B, normal-like $=$ BRCA1 mutation (NKI only)

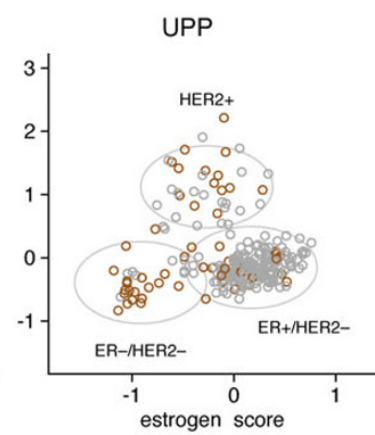

UPP

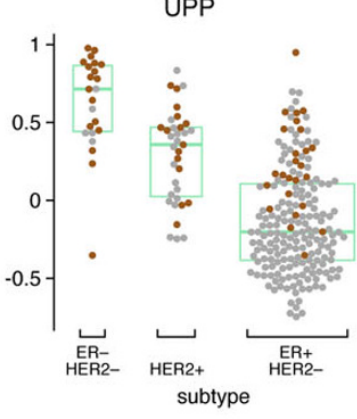

p53 mutation (UPP only)

Breast tumor characterization using module scores. (a) Joint distribution between the estrogen and ERBB2 amplification scores in example datasets. Clusters are identified by Gaussian mixture models with three components. The ellipses correspond to the $95 \%$ cumulative probability around the cluster centers. The clusters are designated as tumor types ER-/ERBB2; HER2+, and ER+/HER2- HER2 ${ }^{+}$tumors show intermediate estrogen scores. (b) Dot histograms showing dependence of proliferation score on the subtypes. The median and quartiles for each group are shown by the box plot. ER//ERBB2 and HER2+ tumors show high proliferation scores, whereas ER+/HER2 tumors show a wide range of proliferation scores. The distributions of the intrinsic subtypes (colored dots), BRCA1 mutations, and p53 mutations are shown in datasets where they are available. ER, estrogen receptor.

metric bootstrapping. Each tumor was automatically classified as estrogen receptor-negative (ER-)/HER2 ${ }^{+}$, HER2 ${ }^{+}$, or $\mathrm{ER}^{+}$ using the maximum posterior probability of membership in the clusters.

\section{Survival analysis}

Survival curves and 5-year survival rates in forest plots were based on Kaplan-Meier estimates, with the Greenwood method used for computing the 95\% confidence intervals [30]. Hazard ratios between two groups were calculated using Cox regression. Stratified Cox regression was used to compute total hazard ratios in forest plots and multivariate analysis, using the dataset as the stratum indicator, thus allowing for different baseline hazard functions between cohorts. Cox regression was also used to compute gene-by-gene associations with survival, treating the log expression measures as continuous explanatory variables. The gene-wise $z$ scores were combined across datasets using the inverse normal metaanalytical methods. Distant relapse-free survival (DRFS) was considered as an event for our survival analysis, which includes distant recurrence, death from breast cancer, death from a cause other than breast cancer, and death from an unknown cause.

\section{Results \\ Prototype-based coexpression module analysis}

To perform this meta-analysis including several heterogeneous datasets and different microarray platforms, we used the concept of coexpression modules. To identify these modules, we applied a supervised approach whereby three 'prototype' genes representing three key biological processes in breast cancer (namely, proliferation, ER, and HER2 amplification signaling) were selected. The genes chosen as their prototypes were, respectively, ESR1, ERBB2, and AURKA (aurorarelated kinase 1, also known as STK6 or STK15).

Using the meta-analysis scheme described above, we were able to identify genes whose expression was significantly associated with each chosen prototype (Additional data file 3 ). The coexpression patterns of the genes are shown by heatmaps in Figure 2 of Additional data file 2. Each module contains highly correlated or anticorrelated genes, as shown by the vertical color patterns. The annotation of the modules 
Table 1

Publicly available gene expression data from breast cancer studies

\begin{tabular}{|c|c|c|c|c|c|c|}
\hline Dataset symbol & Number of arrays & Institution & Reference(s) & Platform & Data source & Number of GenelDs \\
\hline \multicolumn{7}{|c|}{ Genomic platforms } \\
\hline NKI & 337 & $\begin{array}{c}\text { Nederlands Kanker } \\
\text { Instituut (Amsterdam, The } \\
\text { Netherlands) }\end{array}$ & {$[19,20]$} & Agilent & Author's website & 13,120 \\
\hline EMC & 286 & $\begin{array}{c}\text { Erasmus Medical Center } \\
\text { (Rotterdam, The } \\
\text { Netherlands) }\end{array}$ & [21] & Affymetrix U133A & GEO: GSE2034 & 11,837 \\
\hline UPP & 249 & $\begin{array}{l}\text { Karolinksa Institute } \\
\text { (Uppsala, Sweden) }\end{array}$ & {$[3,11]$} & Affymetrix U133A,B & GEO: GSE4922 & 15,684 \\
\hline STOCK & 159 & $\begin{array}{l}\text { Karolinska Institute } \\
\text { (Stockholm, Sweden) }\end{array}$ & {$[3,13]$} & Affymetrix U133A,B & GEO: GSE1456 & 15,684 \\
\hline DUKE & 171 & $\begin{array}{l}\text { Duke University (Durham, } \\
\text { NC, USA) }\end{array}$ & {$[8]$} & Affymetrix U95Av2 & Author's website & 8,149 \\
\hline UCSF & $161+8$ & $\begin{array}{l}\text { University of California at } \\
\text { San Francisco (USA) }\end{array}$ & [9] & cDNA & Author's website & 6,178 \\
\hline UNC & $143+10$ & $\begin{array}{c}\text { University of North } \\
\text { Carolina (Chapel Hill, NC, } \\
\text { USA) }\end{array}$ & [7] & Agilent HuA1 & Author's website & 13,784 \\
\hline $\mathrm{NCH}$ & 135 & $\begin{array}{l}\text { Nottingham City Hospital } \\
\text { (Nottingham, UK) }\end{array}$ & {$[12]$} & Agilent HuA1 & AE: E-UCON-1 & 13,784 \\
\hline STNO & $115+7$ & $\begin{array}{c}\text { Stanford University (Palo } \\
\text { Alto, CA, USA)/Norwegian } \\
\text { Radium Hospital (Oslo, } \\
\text { Norway) }\end{array}$ & [16] & cDNA & Author's website & 5,614 \\
\hline $\mathrm{JRH} 1$ & 99 & $\begin{array}{l}\text { John Radcliffe Hospital } \\
\text { (Oxford, UK) }\end{array}$ & [17] & cDNA & Journal's website & 4,112 \\
\hline $\mathrm{JRH} 2$ & 61 & John Radcliffe Hospital & [18] & Affymetrix $U 133 \mathrm{~A}$ & GEO: GSE2990 & 11,837 \\
\hline $\mathrm{MGH}$ & 60 & $\begin{array}{c}\text { Massachusetts General } \\
\text { Hospital (Boston, MA, } \\
\text { USA) }\end{array}$ & [10] & Agilent & GEO: GSE1379 & 11,421 \\
\hline expO & 239 & $\begin{array}{l}\text { International Genomic } \\
\text { Consortium }\end{array}$ & [41] & Affymetrix U133v2 & GEO: GSE2109 & 16,634 \\
\hline TGIF1 & 49 & EORTC trial 10994 & [5] & Affymetrix U133A & GEO: GSE1561 & 11,837 \\
\hline BWH & $40+7$ & $\begin{array}{c}\text { Brigham and Women's } \\
\text { Hospital (Boston, MA, } \\
\text { USA) }\end{array}$ & [14] & Affymetrix U133v2 & GEO: GSE3744 & 16,634 \\
\hline \multicolumn{7}{|l|}{$\begin{array}{l}\text { Small diagnostic } \\
\text { platforms }\end{array}$} \\
\hline TRANSBIG & 253 & TRANSBIG Consortium & [2] & Agilent & AE: E-TABM-77 & 1,052 \\
\hline EMC2 & 180 & Erasmus Medical Center & [6] & Affymetrix (custom) & GSE3453 & 86 \\
\hline HPAZ & 96 & $\begin{array}{l}\text { Hospital La Paz (Madrid, } \\
\text { Spain) }\end{array}$ & [4] & RT-PCR & Appendix of [4] & 61 \\
\hline \multirow[t]{2}{*}{ Total } & \multirow{2}{*}{\multicolumn{2}{|c|}{$\begin{array}{c}2,865=2,833 \text { carcinomas }+32 \text { nonmalignant } \\
\text { breast tissues }\end{array}$}} & \multicolumn{3}{|c|}{ Number of the union of all GenelDs: } & 17,198 \\
\hline & & & \multicolumn{3}{|c|}{ Number of GenelDs common to genomic platforms: } & 1,963 \\
\hline
\end{tabular}

Datasets UNC, STNO, UCSF, and BWH include a small number of normal breast or fibroadenoma tissue samples. AE, ArrayExpress (accession); Affymetrix, Affymetrix, Inc., Santa Clara, CA, USA; Agilent, Agilent Technologies, Inc., Santa Clara, CA, USA; EORTC, European Organization for Research and Treatment of Cancer; GEO, Gene Expression Omnibus (accession); RT-PCR, reverse transcription-polymerase chain reaction.

shows that they correspond well to the expected biological processes, as many ER-related, HER2-related, and proliferation genes were included in the ER and HER2 signaling and proliferation modules, respectively. For our further analysis, the correlated gene expression measures in a module (which pro- vide redundant information) are averaged into a single number called a 'module score'. 
(a)

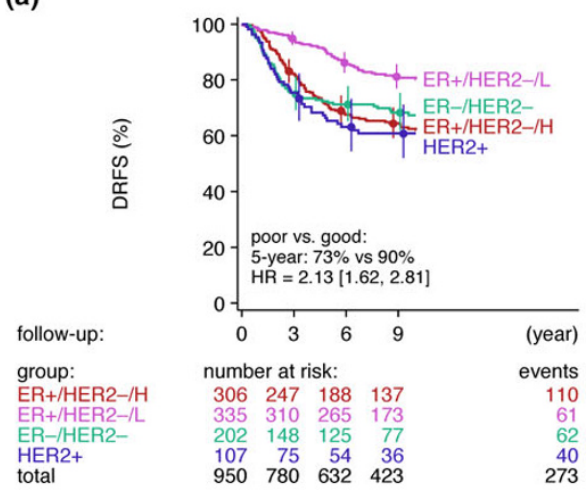

(c)

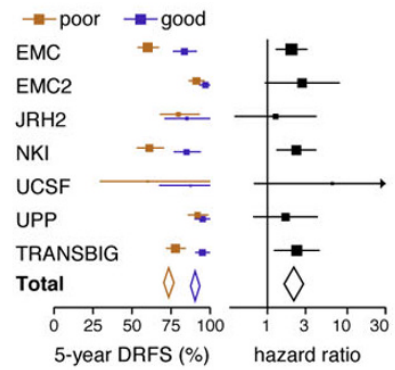

(e)

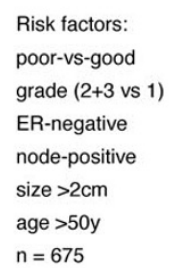

(b)

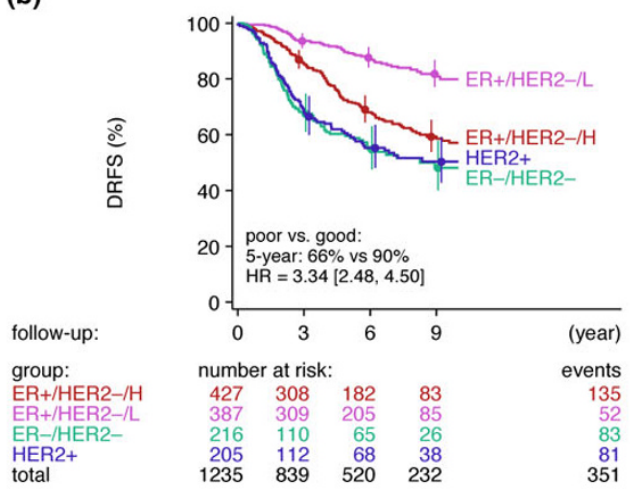

(d)

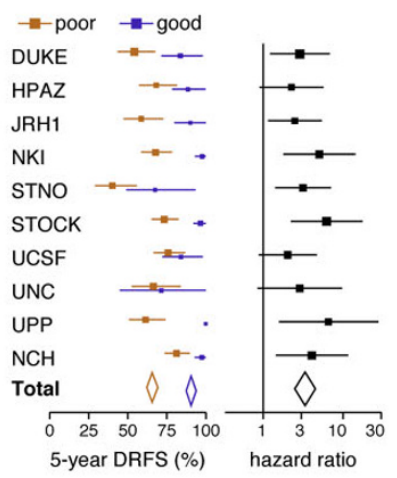

(f)

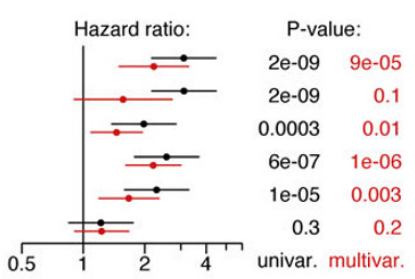

Survival analysis of groups based on module scores. Kaplan-Meier analysis for distant relapse-free survival (DRFS) of systemically untreated (a) and treated (b) patient groups. The $\mathrm{ER}^{+}$subgroup is split into $\mathrm{ER}^{+} / \mathrm{HER} 2^{-} / \mathrm{L}$ and $\mathrm{ER}+/ \mathrm{HER} 2 / \mathrm{H}$ (low and high proliferation, respectively). Vertical bars on the curves are 95\% confidence intervals for the Kaplan-Meier survival estimates. Forest plot representation of the 5-year survival estimates and hazard ratios for DRFS of individual datasets in the systemically untreated (c) and treated (d) populations. The length of horizontal bars and the width of the diamonds of the 'Total' correspond to $95 \%$ confidence intervals. Missing bars are unavailable data. Multivariate analysis representation in which all the variables are available in systemically untreated $(\mathbf{e})$ and treated (f) patients. ER, estrogen receptor; HR, hazard ratio.

\section{Module scores for tumor subtyping}

To automatically assign these large numbers of tumors into the subtypes according to the given module, we applied the Gaussian mixture models [29] to the module scores of the three processes. Only three natural clusters, based on multimodality tests, can be identified. The ER and HER2 module scores were bimodally distributed, but the proliferation module was not. Furthermore, the combination of the ER and HER2 module scores does not produce four clusters that would have been observed if the scores were independent (Figure 1a). Instead, ERBB2+ tumors showed an intermediate level of ER module values, and we therefore did not consider the distinction of ERBB2+ into ER+ ${ }^{+}$or ER- to be supported by continuous value gene expression levels. We will refer to three groups as ER-/HER2-, HER2+ ${ }^{+}$, and ER+/HER2- tumors, which correspond roughly to the intrinsic subtypes of basal-like, her2, and combined luminal A/B subtypes, respectively, as defined by the Stanford group [15].

Concerning proliferation, Figure $1 \mathrm{~b}$ shows that, while ER\% HER2 and HER2 ${ }^{+}$tumors have mostly high proliferation scores, ER+/HER2- tumors display a wide range of values, 
encompassing the low values of normal breast tissue (see dataset UNC) and the high values typical for ER-/HER2- and HER2+ tumors. For our further analysis, we denote the $\mathrm{ER}^{+} /$ HER2- low- and high-proliferation tumors as ER $+/ \mathrm{HER} 2 / \mathrm{L}$ and $\mathrm{ER}^{+} / \mathrm{HER} 2 / \mathrm{H}$, corresponding to the luminal $\mathrm{A}$ and $\mathrm{B}$ subdivisions of the intrinsic subtypes, respectively. Interestingly, we did not see natural clustering (bimodality) in the distribution of proliferation scores as was the case with the ER and ERBB2 modules.

The relationship between module scores and some gene mutations could also be examined. Almost all BRCA1-mutated tumors are confined to ER- tumors (Figure 1b), confirming the hypothesis that ER- ('basal-like') tumors are phenocopies of BRCA1-mutated tumors [14]. This is also supported by the strong overexpression of LMO4, a suppressor of BRCA1 function [31], in ER- tumors. p53 mutations may appear in the three subtypes, but mostly confined to the highly proliferative tumors. It is not clear whether their association with ER-/ HER2 and HER2 + tumors is related to the pathways of these receptors or is merely an indirect effect of the mutations' association with proliferation.

\section{Prognostic value of the molecular subtypes according to the module scores}

The attractiveness of gene expression prognostic signatures for clinical applications comes from their ability to identify a group of patients with a good survival rate that is acceptable to spare patients from aggressive chemotherapy. Here, we investigated whether classifications based on the easily interpretable module scores could achieve such clinical relevance.

Figure 2 shows a Kaplan-Meier analysis for the DRFS of systemically untreated (Figure 2a) patients and those treated (Figure $2 b$ ) with adjuvant chemotherapy and/or endocrine therapy with available clinical information, according to four main subtypes based on the module scores. The ER+/HER2//L subtype showed a much better DRFS than the three others in both untreated and treated populations, with $90 \%$ of patients alive at 5 years of follow-up. Because there is no statistical difference in survival between the ER', $\mathrm{HER}^{+}{ }^{+}$, and $\mathrm{ER}+/ \mathrm{HER} 2 / \mathrm{H}$ subtypes and because the risk of recurrence for patients in these groups is clinically still too high, we pooled them into the 'poor' prognosis group, in contrast to the 'good' ER+/HER2/L subtype, for further survival analysis. The consistency of the prognostic value across datasets is demonstrated by the forest plots in Figures $2 \mathrm{c}$ and $2 \mathrm{~d}$, where the results of the analysis of individual datasets are concisely summarized by the 5-year survival estimates and hazard ratios between the 'good' and 'poor' groups. Interestingly, the 'good' prognosis group showed a better DRFS than the 'poor' prognosis group in both untreated and systemically treated populations.

The interactions between the module-based risk groups and conventional clinicopathological prognostic variables are tested in multivariable Cox regression analysis for DRFS in both untreated (Figure 2e) and treated (Figure 2f) populations. The module-based classification added a strong prognostic effect over all other clinical factors. Confirming previous studies [18,32], the effect of histological grade is much reduced and can be explained by the refinement of intermediate grade into two groups with very different survival rates. Interestingly, lymph node status and tumor size remain as independent prognostic factors.

\section{Dissecting gene expression prognostic signatures according to the module scores}

Although Fan and colleagues [25] noted the similarity of the performance and patient classifications of the intrinsic subtypes and four prognostic signatures on the same dataset, they did not provide a biological rationale for this finding. In our study, we performed more detailed and extensive analysis to better understand how disparate gene lists may give rise to potentially equivalent prognostic signatures.

Using our meta-analytical approach, we first sought to identify individual genes that were associated with survival by calculating the meta-analytical $z$ scores of gene-by-gene Cox regression. To gain further insight into the biological significance of these prognostic genes, we investigated their correlation with the coexpression module prototypes. We were able to identify 524 genes that were significantly associated with survival, even under a stringent Bonferroni multiple testing correction (data not shown). Of the 524 genes, $71 \%$ were strongly coexpressed with proliferation, $26 \%$ with $\mathrm{ER}$, and $2.2 \%$ with ERBB2 prototypes, highlighting the importance of proliferation-related genes for prognostication in breast cancer.

A similar analysis was performed with respect to several published prognostic signatures (Table 2). Indeed, many of the genes included in these signatures were confirmed to be individually prognostic in the whole dataset collection (Figure 3 of Additional data file 2). Interestingly, many of these individually prognostic genes were also highly correlated with the proliferation module prototype and not with the other two modules, suggesting that proliferation may be the common driving force of several prognostic signatures.

To further demonstrate our hypothesis, we divided each signature into two 'partial signatures': one with only proliferation genes and the other with the complementary nonproliferation genes (Figure 3; see Figure 4 of Additional data file 2 for detailed analysis). Interestingly, when only proliferation genes were used, the overall performance was not degraded; in fact, it even improved for some signatures (p53-32) in both untreated (Figure 3a) and treated (Figure 3c) populations. In contrast, the nonproliferation partial signatures typically showed degraded performance (Figures $3 \mathrm{~b}$ and $3 \mathrm{~d}$ ). These results show that proposed signatures may contain genes that are unnecessary or even detrimental to their performance. 
Figure 3

(a)

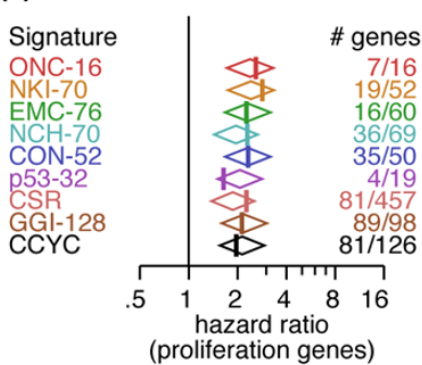

Untreated, $n=695$

(c)

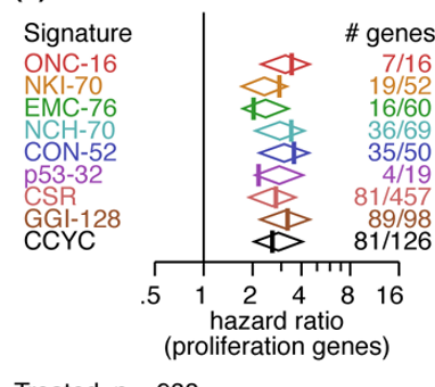

Treated, $\mathrm{n}=938$ (b)

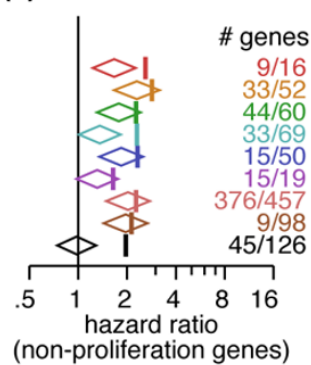

(d)

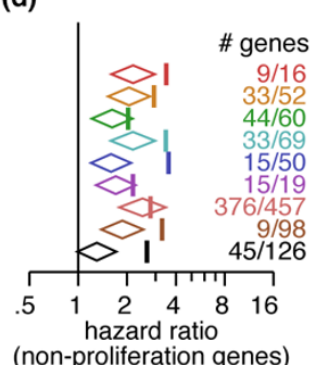

(non-proliferation genes)
Signature comparison. The prognostic performance of the signatures is compared by the forest plots of hazard ratio and plotted as vertical color bars for comparison. Most signatures show similar performance. Prognostic performance for distant relapse-free survival (DRFS) of the signatures using partial signatures containing only proliferation genes in the untreated (a) and treated (c) populations. The performance of most signatures is not degraded; in fact, it is improved for p53-32. Prognostic performance for DRFS of the signatures using partial signatures containing nonproliferation genes in the untreated (b) and treated (d) populations.

These results thus extend the findings of Fan and colleagues [25] to a much larger sample size and for several additional signatures, revealing for the first time the importance of proliferation genes as a common driving force behind the performance of all of the prognostic signatures studied in this investigation.

Finally, the relationship between prognostic signatures and the molecular classification based on the coexpression modules was investigated by looking at the risk classifications on the plots of proliferation scores versus the molecular subtypes shown in Figure 4 (see Figure 4 of Additional data file 2 for analysis on all datasets). Most signatures identified the lowproliferation subset of ER+/HER2- tumors as low-risk, whereas almost all high-proliferation ER+, ER-/HER2', and HER2+ tumors were classified as high-risk. These results suggest that these prognostic signatures function mostly by identifying tumors that have high expression of proliferation genes, regardless of the subtyping based on ER or HER2. They still correctly classify ER-/HER2 and HER2 ${ }^{+}$as high-risk by virtue of elevated expression of proliferation genes.

\section{Discussion}

Several breast cancer studies have generated a large number of arrays with complex genomic data, and an initial effort was made to compare the prognostic performance of the intrinsic subtypes and four signatures in one dataset [25]. In the present meta-analysis, we analyzed data from 2,833 patients to have the power to address the following questions: How are different signatures related with respect to prognostication? Should clinical, pathological, and currently used biomarkers be integrated into this process? What is the role of individual genes in a signature, and what is their biological meaning?

Using our meta-analytical approach, we confirmed the presence of four stable breast cancer molecular subtypes as originally reported by Perou and colleagues [33], whereas the normal-like subtype was not verified. Both ER-/HER2 and HER2 ${ }^{+}$subtypes were characterized by high proliferation, whereas the ER+/HER2 subtype was divided into low- and high-proliferation tumors with different clinical outcomes. The widely observed prognostic powers of ER and HER2 are therefore only indirect effects.

Furthermore, the above results have important clinical implications since they suggest that all investigated prognostic signatures are equivalent. This will be further validated when the results from the currently accruing MINDACT (Microarray in Node-Negative Disease May Avoid Chemotherapy) [34] and TAILORX (Trial Assigning IndividuaLized Options for Treatment [Rx]) [35] trials are reported. For the ER-/HER2 and HER2 ${ }^{+}$patients, new prognostic signatures, which do not rely on proliferation genes, are urgently needed. Initial efforts to improve prognosis in the above high-risk subgroups were recently reported $[36,37]$.

Moreover, rather than treating the signatures as black boxes, the connection to the breast cancer biology has been elucidated. Using this approach, we demonstrated that several previously reported prognostic signatures, despite the disparity in their gene lists, carry similar information with regard to prognostication. Although it may be argued that microarray measurements are merely alternative ways to monitor well-known processes such as proliferation, ER, or HER2 signaling, their results are not perfectly concordant with conventional variables. For example, although the proliferation module score and histological grade both aim to measure cell proliferation, the former is more informative [18]. We observed that HER2+ tumors showed intermediate ER module activity, which is not obvious from the traditional ER and HER2 status using conventional assays. These examples suggest that the assessment of several genes from a coexpression module may provide a more accurate quantification of a whole transcriptional process than using single-gene markers or histopathological variables. 
Table 2

Prognostic signatures

\begin{tabular}{lcccc}
\hline Signature symbol & Reference & Associated variables in gene selection procedure & \multicolumn{2}{c}{ Number of genes } \\
\hline ONC-16 & & & Original probes & Mapped to genelD \\
NKI-70 & {$[42]$} & Biological knowledge; refined by patient outcome & 16 & 16 \\
EMC-76 & {$[19]$} & Patient outcome & 70 & 52 \\
NCH-70 & {$[21]$} & Patient outcome, stratified by estrogen receptor status & $60+16$ & 70 \\
CON-52 & {$[12]$} & Patient outcome & 52 & 69 \\
p53-32 & {$[43]$} & Patient outcome, consensus & 32 & 50 \\
CSR & {$[11]$} & p53 mutation & 512 & 19 \\
GGI-128 & {$[24]$} & Fibroblast core serum response & 128 & 457 \\
CCYC & {$[18]$} & Histological grade & NA & 98 \\
\hline
\end{tabular}

NA, not applicable.

Blamey [38] distinguished independent prognostic factors into those related to the extent of tumor progression (such as lymph node status and tumor size) and those related to a tumor's intrinsic aggressiveness (such as histological grade and mitotic rate) and found only that the prognostic roles of many markers, such as ER, progesterone receptor, and p53, were overshadowed by histological grade. Our results confirmed these observations, as proliferation genes are even better indicators of tumor grade [18]. The proliferation score already contains the poor prognosis information attributable to various sources: for example, ERBB2 amplification (with or without BRCA1 mutation), p53 mutation, or yet unknown factors specifically affecting half of ER+ (luminal) tumors. We still see the prognostic effect of lymph node status and tumor size, suggesting that they influence outcome through their own independent paths.

Despite the lack of direct prognostic impact of ER and ERBB2 genes, the coexpression modules for these processes that we identified are still useful. Genes in the proliferation module are already targeted by several chemotherapeutic agents, but less

Figure 4
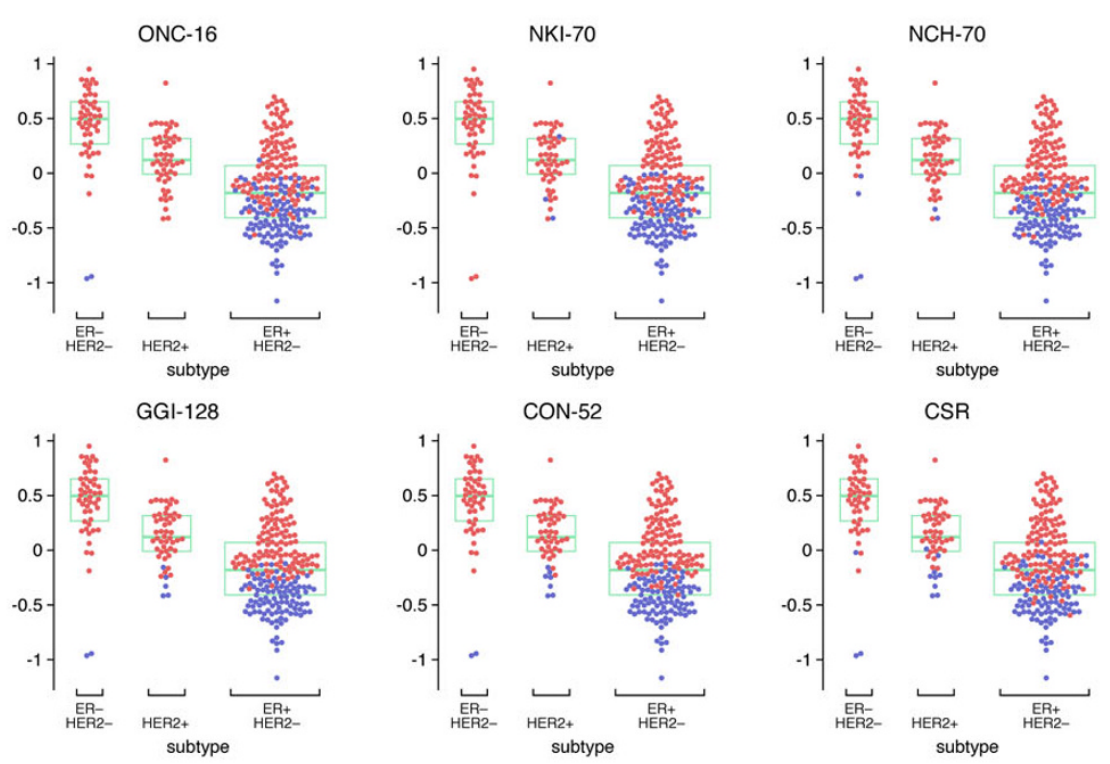

Patient classifications made by example signatures applied to representative datasets, showing that the different signatures are essentially detecting as low-risk the low-proliferation subset of ER+/ERBB2- tumors. ER, estrogen receptor. 
harmful drugs are more desirable. ER+/HER2- tumors are treatable to some extent by hormone therapy [39] (targeting ESR1 signaling), and HER2 + tumors by trastuzumab [40] (targeting ERBB2). However, drugs specifically targeting ER-/ HER2 tumors have not yet been established. Furthermore, the fact that many breast tumors remain unresponsive to existing drugs warrants further searches for alternative targets, possibly compensatory genes in the same pathway. Our analysis provides lists of genes coexpressed with these two processes, and these lists should be more stable than previously published ones because they are identified from a large data collection from multiple platforms.

Finally, we have also shown that using coexpression modules is a versatile tool for unifying apparently disparate results. Although coexpression does not imply direct physical interaction, the highly correlated genes in a module can be considered surrogate markers of one another and of the same underlying transcriptional process. Consequently, newly published signatures in the future can be perceived in the light of well-known modules, and a new, equivalently prognostic set of markers can be devised based on subsets of these lists.

\section{Conclusion}

In summary, this study objectively evaluates several published signatures in independent cohorts from diverse microarray platforms and unifies results of previous gene expression studies in breast cancer. With respect to clinical application, we revealed connections and equivalence between traditional prognostic factors, expression-based subtyping, and prognostic signatures and provided evidence that these signatures should be tested for their ability to spare adjuvant chemotherapy mainly in the low-proliferation subgroup of patients with $\mathrm{ER}^{+}$tumors. With respect to disease biology, we consolidated the gene lists of the major processes, providing more reliable candidates for biomarkers and therapeutic targets than those produced by single-dataset studies. Finally, we provided a new methodological framework, also applicable to other diseases, for using heterogeneous microarray datasets to uncover consistent biological relationships and to consolidate proposed signatures.

\section{Competing interests}

$\mathrm{CS}, \mathrm{MD}$, and MP are named inventors on a patent application for the genomic grade signature used in this study. The other authors declare that they have no competing interests.

\section{Authors' contributions}

PW helped to design the overall study, compile and curate the datasets, design the statistical approaches, perform the computational analysis, and develop the prototype genes and biological interpretation. CS helped to design the overall study and provide expertise in clinical breast oncology. PW and CS contributed equally to this work. MD helped to design the overall study, design the statistical approaches, and perform the computational analysis. SK and TS helped to compile and curate the datasets. DRG helped to design the statistical approaches. SP, FS, BH-K, and $\mathrm{CD}$ helped to perform the computational analysis. PF helped to develop the prototype genes and biological interpretation. MP and MI helped to provide expertise in clinical breast oncology. All authors contributed to the preparation of the manuscript and read and approved the final manuscript.

\section{Additional files}

The following Additional files are available online:

\section{Additional file 1}

Supplementary methods. Supplementary methods including the following sections: 'Probe annotation and gene matching', 'Preprocessing of expression values', 'Identifying coexpression modules', 'Module scores', 'Clustering and multimodality tests', 'Survival analysis', 'Cell-cycle periodicity' and 'Cross-platform applications of signatures'.

See http://www.biomedcentral.com/content/ supplementary/bcr2124-S1.pdf

\section{Additional file 2}

Supplementary results. Supplementary Results including Supplementary Figures 1-5 and the results from the 'Combined prediction by pairs of signatures' (Supplementary Figure 6).

See http://www.biomedcentral.com/content/ supplementary/bcr2124-S2.pdf

\section{Additional file 3}

ESR1, ERBB2 and proliferation coexpression modules. The spreadsheet describes the ESR1, ERBB2 and proliferation (AURKA) coexpression modules. The columns are described in the first lines starting by '\#' in the text file.

See http://www.biomedcentral.com/content/ supplementary/bcr2124-S3.txt

\section{Acknowledgements}

This work was supported by the European Commission Framework Program VI (FP6-LSHC-CT-2004-503426) (PW and FS), by the National Center of Competence in Research Molecular Oncology of the Swiss National Science Foundation (MD, TS, and SK), by the MEDIC Foundation (PF and CS), by the Belgian National Foundation for Cancer Research (FNRS) (BH-K, CD, and CS), and by the Estée Lauder Breast Cancer Research Foundation (BCRF) (CS). We thank Sandra FloresUrushima for initial work in dataset collection. We dedicate this work to Hans-Martin Schultze, who started the preliminary analysis but succumbed prematurely to metastasis of melanoma. 


\section{References}

1. Bild AH, Yao G, Chang JT, Wang Q, Potti A, Chasse D, Joshi MB, Harpole D, Lancaster JM, Berchuck A, Olson JA Jr, Marks JR, Dressman HK, West M, Nevins JR: Oncogenic pathway signatures in human cancers as a guide to targeted therapies. Nature 2006, 439:353-357.

2. Buyse $M$, Loi $S$, van't Veer L, Viale G, Delorenzi M, Glas AM, d'Assignies MS, Bergh J, Lidereau R, Ellis P, Harris A, Bogaerts J, Therasse P, Floore A, Amakrane M, Piette F, Rutgers E, Sotiriou C, Cardoso F, Piccart MJ, TRANSBIG Consortium: Validation and clinical utility of a 70-gene prognostic signature for women with node-negative breast cancer. I Natl Cancer Inst 2006, 98:1183-1192.

3. Calza S, Hall P, Auer G, Bjohle J, Klaar S, Kronenwett U, Liu ET, Miller L, Ploner A, Smeds J, Bergh J, Pawitan Y: Intrinsic molecular signature of breast cancer in a population-based cohort of 412 patients. Breast Cancer Res 2006, 8:R34.

4. Espinosa E, Vara JA, Redondo A, Sanchez JJ, Hardisson D, Zamora P, Pastrana FG, Cejas P, Martinez B, Suarez A, Calero F, Barón MG: Breast cancer prognosis determined by gene expression profiling: a quantitative reverse transcriptase polymerase chain reaction study. J Clin Oncol 2005, 23:7278-7285.

5. Farmer $P$, Bonnefoi $H$, Becette $V$, Tubiana-Hulin M, Fumoleau $P$, Larsimont D, Macgrogan G, Bergh J, Cameron D, Goldstein D, Duss S, Nicoulaz AL, Brisken C, Fiche M, Delorenzi M, Iggo R: Identification of molecular apocrine breast tumours by microarray analysis. Oncogene 2005, 24:4660-4671.

6. Foekens JA, Atkins D, Zhang Y, Sweep FC, Harbeck N, Paradiso A, Cufer T, Sieuwerts AM, Talantov D, Span PN, Tjan-Heijnen VC, Zito AF, Specht K, Hoefler H, Golouh R, Schittulli F, Schmitt M, Beex LV, Klijn JG, Wang Y: Multicenter validation of a gene expression-based prognostic signature in lymph node-negative primary breast cancer. J Clin Oncol 2006, 24:1665-1671.

7. Hu Z, Fan C, Oh DS, Marron JS, He X, Qaqish BF, Livasy C, Carey LA, Reynolds E, Dressler L, Nobel A, Parker J, Ewend MG, Sawyer LR, Wu J, Liu Y, Nanda R, Tretiakova M, Ruiz Orrico A, Dreher D, Palazzo JP, Perreard L, Nelson E, Mone M, Hansen H, Mullins M, Quackenbush JF, Ellis MJ, Olopade OI, Bernard PS, Perou CM: The molecular portraits of breast tumors are conserved across microarray platforms. BMC Genomics 2006, 7:96.

8. Huang $E$, Ishida S, Pittman J, Dressman $H$, Bild A, Kloos M, D'Amico M, Pestell RG, West M, Nevins JR: Gene expression phenotypic models that predict the activity of oncogenic pathways. Nat Genet 2003, 34:226-230.

9. Korkola JE, DeVries S, Fridlyand J, Hwang ES, Estep AL, Chen YY, Chew KL, Dairkee SH, Jensen RM, Waldman FM: Differentiation of lobular versus ductal breast carcinomas by expression microarray analysis. Cancer Res 2003, 63:7167-7175.

10. Ma XJ, Wang Z, Ryan PD, Isakoff SJ, Barmettler A, Fuller A, Muir B, Mohapatra G, Salunga R, Tuggle JT, Tran Y, Tran D, Tassin A, Amon P, Wang W, Wang W, Enright E, Stecker K, Estepa-Sabal E, Smith B, Younger J, Balis U, Michaelson J, Bhan A, Habin K, Baer TM, Brugge J, Haber DA, Erlander MG, Sgroi DC: A twogene expression ratio predicts clinical outcome in breast cancer patients treated with tamoxifen. Cancer Cell 2004, 5:607-616.

11. Miller LD, Smeds J, George J, Vega VB, Vergara L, Ploner A, Pawitan $Y$, Hall P, Klaar S, Liu ET, Bergh J: An expression signature for p53 status in human breast cancer predicts mutation status, transcriptional effects, and patient survival. Proc Natl Acad Sci USA 2005, 102:13550-13555.

12. Naderi A, Teschendorff AE, Barbosa-Morais NL, Pinder SE, Green AR, Powe DG, Robertson JF, Aparicio S, Ellis IO, Brenton JD, Caldas C: A gene-expression signature to predict survival in breast cancer across independent data sets. Oncogene 2007, 26:1507-1516.

13. Pawitan $\mathrm{Y}$, Bjohle J, Amler L, Borg AL, Egyhazi S, Hall P, Han X, Holmberg L, Huang F, Klaar S, Liu ET, Miller L, Nordgren $H$, Ploner A, Sandelin K, Shaw PM, Smeds J, Skoog L, Wedrén S, Bergh J: Gene expression profiling spares early breast cancer patients from adjuvant therapy: derived and validated in two population-based cohorts. Breast Cancer Res 2005, 7:R953-964.

14. Richardson AL, Wang ZC, De Nicolo A, Lu X, Brown M, Miron A, Liao X, Iglehart JD, Livingston DM, Ganesan S: X chromosomal abnormalities in basal-like human breast cancer. Cancer Cell 2006, 9:121-132.

15. Sorlie T, Perou CM, Tibshirani R, Aas T, Geisler S, Johnsen H, Hastie T, Eisen MB, Rijn M van de, Jeffrey SS, Thorsen T, Quist $H$, Matese JC, Brown PO, Botstein D, Eystein Lønning P, BørresenDale AL: Gene expression patterns of breast carcinomas distinguish tumor subclasses with clinical implications. Proc Nat/ Acad Sci USA 2001, 98:10869-10874.

16. Sorlie T, Tibshirani R, Parker J, Hastie T, Marron JS, Nobel A, Deng S, Johnsen H, Pesich R, Geisler S, Demeter J, Perou CM, Lønning PE, Brown PO, Børresen-Dale AL, Botstein D: Repeated observation of breast tumor subtypes in independent gene expression data sets. Proc Natl Acad Sci USA 2003, 100:8418-8423.

17. Sotiriou C, Neo SY, McShane LM, Korn EL, Long PM, Jazaeri A, Martiat $P$, Fox SB, Harris AL, Liu ET: Breast cancer classification and prognosis based on gene expression profiles from a population-based study. Proc Natl Acad Sci USA 2003, 100:10393-10398.

18. Sotiriou C, Wirapati P, Loi S, Harris A, Fox S, Smeds J, Nordgren $\mathrm{H}$, Farmer P, Praz V, Haibe-Kains B, Desmedt C, Larsimont D, Cardoso F, Peterse H, Nuyten D, Buyse M, Vijver MJ Van de, Bergh J, Piccart M, Delorenzi M: Gene expression profiling in breast cancer: understanding the molecular basis of histologic grade to improve prognosis. J Natl Cancer Inst 2006, 98:262-272.

19. van't Veer LJ, Dai H, Vijver MJ van de, He YD, Hart AA, Mao M, Peterse HL, Kooy K van der, Marton MJ, Witteveen AT, Schreiber GJ, Kerkhoven RM, Roberts C, Linsley PS, Bernards R, Friend SH: Gene expression profiling predicts clinical outcome of breast cancer. Nature 2002, 415:530-536.

20. Vijver MJ van de, He YD, van't Veer LJ, Dai H, Hart AA, Voskuil DW, Schreiber GJ, Peterse JL, Roberts C, Marton MJ, Parrish M, Atsma D, Witteveen A, Glas A, Delahaye L, Velde T van der, Bartelink H, Rodenhuis S, Rutgers ET, Friend SH, Bernards R: A geneexpression signature as a predictor of survival in breast cancer. N Engl J Med 2002, 347:1999-2009.

21. Wang $Y$, Klijn JG, Zhang $Y$, Sieuwerts AM, Look MP, Yang F, Talantov D, Timmermans M, Meijer-van Gelder ME, Yu J, Jatkoe T, Berns EM, Atkins D, Foekens JA: Gene-expression profiles to predict distant metastasis of lymph-node-negative primary breast cancer. Lancet 2005, 365:671-679.

22. Paik S, Tang G, Shak S, Kim C, Baker J, Kim W, Cronin M, Baehner FL, Watson D, Bryant J, Costantino JP, Geyer CE Jr, Wickerham DL, Wolmark N: Gene expression and benefit of chemotherapy in women with node-negative, estrogen receptor-positive breast cancer. J Clin Oncol 2006, 24:3726-3734.

23. Chang HY, Nuyten DS, Sneddon JB, Hastie T, Tibshirani R, Sorlie $T$, Dai H, He YD, van't Veer LJ, Bartelink H, Rijn M van de, Brown $\mathrm{PO}$, Vijver MJ van de: Robustness, scalability, and integration of a wound-response gene expression signature in predicting breast cancer survival. Proc Natl Acad Sci USA 2005, 102:3738-3743.

24. Chang HY, Sneddon JB, Alizadeh AA, Sood R, West RB, Montgomery K, Chi JT, Rijn M van de, Botstein D, Brown PO: Gene expression signature of fibroblast serum response predicts human cancer progression: similarities between tumors and wounds. PLoS Biol 2004, 2:E7.

25. Fan C, Oh DS, Wessels L, Weigelt B, Nuyten DS, Nobel AB, van't Veer LJ, Perou CM: Concordance among gene-expressionbased predictors for breast cancer. N Engl J Med 2006, 355:560-569.

26. Maglott D, Ostell J, Pruitt KD, Tatusova T: Entrez Gene: genecentered information at NCBI. Nucleic Acids Res 2007:D26-31.

27. MAQC Consortium, Shi L, Reid LH, Jones WD, Shippy R, Warrington JA, Baker SC, Collins PJ, de Longueville F, Kawasaki ES, Lee KY, Luo Y, Sun YA, Willey JC, Setterquist RA, Fischer GM, Tong W, Dragan YP, Dix DJ, Frueh FW, Goodsaid FM, Herman D, Jensen RV, Johnson CD, Lobenhofer EK, Puri RK, Schrf U, ThierryMieg J, Wang C, Wilson M, et al.: The MicroArray Quality Control (MAQC) project shows inter- and intraplatform reproducibility of gene expression measurements. Nat Biotechnol 2006, 24:1151-1161.

28. Hedges LV, Olkin I: Statistical Methods for Meta-Analysis London: Academic Press; 1985

29. McLachlan G, Peel D: Finite Mixture Mode/s New York: John Wiley \& Sons, Inc; 2000.

30. Therneau TM: A Package for Survival Analysis in S Rochester MN: Mayo Clinic Foundation; 1999. 
31. Sum EY, Peng B, Yu X, Chen J, Byrne J, Lindeman GJ, Visvader JE: The LIM domain protein LMO4 interacts with the cofactor CtIP and the tumor suppressor BRCA1 and inhibits BRCA1 activity. J Biol Chem 2002, 277:7849-7856.

32. Ivshina AV, George J, Senko O, Mow B, Putti TC, Smeds J, Lindahl $T$, Pawitan $Y$, Hall P, Nordgren H, Wong JE, Liu ET, Bergh J, Kuznetsov VA, Miller LD: Genetic reclassification of histologic grade delineates new clinical subtypes of breast cancer. Cancer Res 2006, 66:10292-10301.

33. Perou CM, Sorlie T, Eisen MB, Rijn M van de, Jeffrey SS, Rees CA, Pollack JR, Ross DT, Johnsen H, Akslen LA, Fluge O, Pergamenschikov A, Williams C, Zhu SX, Lønning PE, Børresen-Dale AL, Brown PO, Botstein D: Molecular portraits of human breast tumours. Nature 2000, 406:747-752.

34. Bogaerts J, Cardoso F, Buyse M, Braga S, Loi S, Harrison JA, Bines J, Mook S, Decker N, Ravdin P, Therasse P, Rutgers E, van't Veer LJ, Piccart M, TRANSBIG consortium: Gene signature evaluation as a prognostic tool: challenges in the design of the MINDACT trial. Nat Clin Pract Oncol 2006, 3:540-551.

35. Sparano JA: TAILORx: trial assigning individualized options for treatment (Rx). Clin Breast Cancer 2006, 7:347-350.

36. Teschendorff AE, Miremadi A, Pinder SE, Ellis IO, Caldas C: An immune response gene expression module identifies a good prognosis subtype in estrogen receptor negative breast cancer. Genome Biol 2007, 8:R157.

37. Alexe G, Dalgin GS, Scanfeld D, Tamayo P, Mesirov JP, DeLisi C, Harris L, Barnard N, Martel M, Levine AJ, Ganesan S, Bhanot G: High expression of lymphocyte-associated genes in nodenegative HER2+ breast cancers correlates with lower recurrence rates. Cancer Res 2007, 67:10669-10676.

38. Blamey RW: The design and clinical use of the Nottingham Prognostic Index in breast cancer. The Breast 1996, 5:156-157

39. Tamoxifen for early breast cancer: an overview of the randomised trials. Early Breast Cancer Trialists' Collaborative Group. Lancet 1998, 351:1451-1467.

40. Romond EH, Perez EA, Bryant J, Suman VJ, Geyer CE Jr, Davidson NE, Tan-Chiu E, Martino S, Paik S, Kaufman PA, Swain SM, Pisansky TM, Fehrenbacher L, Kutteh LA, Vogel VG, Visscher DW, Yothers G, Jenkins RB, Brown AM, Dakhil SR, Mamounas EP, Lingle WL, Klein PM, Ingle JN, Wolmark N: Trastuzumab plus adjuvant chemotherapy for operable HER2-positive breast cancer. $N$ Engl J Med 2005, 353:1673-1684.

41. International Genomics Consortium [http://www.intgen.org]

42. Paik S, Shak S, Tang G, Kim C, Baker J, Cronin M, Baehner FL, Walker MG, Watson D, Park T, Hiller W, Fisher ER, Wickerham $\mathrm{DL}$, Bryant J, Wolmark N: A multigene assay to predict recurrence of tamoxifen-treated, node-negative breast cancer. $N$ Engl J Med 2004, 351:2817-2826.

43. Teschendorff AE, Naderi A, Barbosa-Morais NL, Pinder SE, Ellis IO, Aparicio S, Brenton JD, Caldas C: A consensus prognostic gene expression classifier for ER positive breast cancer. Genome Biol 2006, 7:R101.

44. Whitfield ML, George LK, Grant GD, Perou CM: Common markers of proliferation. Nat Rev Cancer 2006, 6:99-106. 